\title{
Hypercholesterolaemia in pregnancy as a predictor of adverse pregnancy outcome
}

\author{
Adegbesan-Omilabu Maymunah ${ }^{1}$, Okunade Kehinde ${ }^{1}$, Gbadegesin Abidoye $^{2}$, Akinsola Oluwatosin ${ }^{3}$
}

1. Department of Obstetrics \& Gynaecology, Lagos University Teaching Hospital (LUTH), Lagos, Nigeria

2. Department of Obstetrics \& Gynaecology, Lagos State University Teaching Hospital (LASUTH), Lagos, Nigeria

3. Department of Community Health, Lagos University Teaching Hospital (LUTH), Lagos, Nigeria

\begin{abstract}
Background: Prevention of viable spontaneous preterm birth and low birth weight through screening is one of the key aims of antenatal care as these have implications for the child, mother and society. If women can be identified to be at high risk of these adverse birth outcomes in early pregnancy, they can be targeted for more intensive antenatal surveillance and prophylactic interventions.

Objectives: This study is therefore aimed to determine the association between elevated maternal serum cholesterol level in pregnancy and adverse pregnancy outcome.

Methods: It was a prospective observational cohort study in which eligible participants were enrolled at gestational age of 14 to 20 weeks. Blood samples were obtained to measure total serum cholesterol concentrations and the sera were then analyzed enzymatically by the cholesterol oxidase: p-aminophenazone (CHOD PAP) method. Pregnancy outcomes were obtained by extraction from medical records and the labour ward register.

Results: The incidences of the two adverse pregnancy outcomes examined in the study (preterm births and low birth weight (LBW) in term neonates) were $8.0 \%$ and $14.4 \%$ respectively. Preterm birth was 6.89 -times more common in mothers with high cholesterol than in control mothers with normal total cholesterol level $(38.5 \%$ versus $5.4 \%$, $\mathrm{P}=0.029)$ while $\mathrm{LBW}$ was

7.99-times more common in mothers with high total maternal cholesterol than in mothers with normal cholesterol $(87.5 \%$ versus $10.5 \%, \mathrm{P}=0.019)$.

Conclusion: We can infer that the high maternal serum cholesterol (hypercholesterolaemia) is associated with preterm delivery/low birth weight (LBW) in term infants. However, further validation of these findings with more robust prospective and longitudinal characterization of maternal serum cholesterol profiles is required in subsequent investigations.
\end{abstract}

Keywords: Adverse birth outcome, cholesterol, hypercholesterolaemia, LBW, preterm births

DOI: http://dx.doi.org/10.4314/ahs.v14i4.28

\section{Introduction}

Preterm birth and fetal growth restriction affect over $10 \%$ of all pregnancies and leads to significant neonatal morbidity and mortality ${ }^{1}$. Prevention of viable spontaneous preterm birth and low birth weight through screening is one of the key aims of antenatal care as these have implications for the child, mother and

\section{Corresponding author:}

Kehinde S. Okunade

Department of Obstetrics \& Gynaecology,

Lagos University Teaching

Hospital (LUTH), Lagos, Nigeria

Phone numbers: 08034728139, 08177440443

E-mail address: kokokenny@yahoo.com,

kehindeokunade@gmail.com society. If women can be identified to be at high risk of these adverse birth outcomes in early pregnancy, they can be targeted for more intensive antenatal surveillance and prophylactic interventions (primary prevention).

Maternal cholesterol is essential for both the hormonal and physical changes of early pregnancy ${ }^{2}$. Circulating low-density lipoprotein cholesterol is the chief substrate for placental progesterone biosynthesis ${ }^{3,4}$. Even though some longitudinal studies have documented that total cholesterol increases substantially during the second and third trimesters of pregnancy ${ }^{5-7}$, it is still presently not known whether optimal levels of maternal serum cholesterol during pregnancy can be defined. This physiologic hypercholesterolemia of later pregnancy suggests an adaptive function for pregnancy maintenance or fetal growth ${ }^{8}$. Conversely, maternal hypercholesterolemia is also suspected to be injurious, because concentrations $>300 \mathrm{mg} / \mathrm{dL}$ have been linked 
to increased cholesterol deposition in the fetal aorta ${ }^{9} ; 18$ to 35 years and have a singleton gestation. the "fetal origins hypothesis" links this phenomenon to Exclusion criteria included pregnant women with mulsubsequently increased risk for cardiovascular disease tiple gestations, history of diabetes or hypertension, in the adult offspring ${ }^{10-12}$. It is also reasoned that this el- HIV, current or previous history of smoking, othevated maternal cholesterol may have a disproportion- er described substance use, and reports of previous ate impact during critical periods for placentation abnormal pregnancy history. Additional patients were and early neuroepithelial expansion ${ }^{13}$.

Various studies have reported a possibly increased risk for prematurity and impaired fetal growth ${ }^{14-16}$ with very high maternal cholesterol level but the effects of hypercholesterolemia on the metabolic process of tissues that support the fetus, the placenta, and the yolk sac have yet to be established, and those effects could markedly the outcome of pregnancy and long-term health issues. This study will thus investigate the ef-
fect of a higher than normal level of maternal serum cholesterol during gestation on two important adverse pregna omes (preterm births and low birth weight) and thereafter describe a generic framework for combining this screening information with designing a prophylactic intervention in the fu-

\section{Materials \& Methods} Labour ward complex of a tertiary hospital in Southwest Nigeria. It was a prospective observational cohort study of pregnancy outcome in young, generally healthy pregnant women attending the antenatal clinic of the hospital over a period of 12 months.

The sample size $(\mathrm{N})$ for the study was determined using the statistical formula by Schlesselman ${ }^{17}$. While 320 participants were enrolled between gestational ages of 14 and 20. The women were enrolled during thi

period of pregnancy in order to carefully isolate the All quantitative data were entered in computer and mothers' inherent cholesterol levels from the natural analysed using SPSS version 17 for windows ${ }^{20}$. Deincreases in terol levels that occur physiologically during the late second and third trimesters of pregnancy. Women were also not recruited in the first trimester (before 14 ing until the early second trimester which thus sugges that our study findings can be of benefit mostly around that usual time of presentation.

Eligible participants were pregnant women aged

Venous blood samples were obtained from fasting patient in the morning to measure total serum cholesterol concentrations between 14 and 20 weeks' gestation Samples were collected in lithium heparin specimen bottles. Total Cholesterol in serum was then analyzed enzymatically by the cholesterol oxidase: p-aminophenazone (CHOD-PAP) method using reagents from the manufacturer (BIOLABO SA, 02160, Maizy, France)

The reference value for normal serum cholesterol is $200-239 \mathrm{mg} / \mathrm{dl}^{19}$. Thus, high maternal serum cholesterol pregnancies were defined as those in which maternal serum cholesterol level was above $239 \mathrm{mg} / \mathrm{dL}$. Gestational duration was based upon gestation from participants' last normal menstrual period confirmed or modified by ultrasound. Preterm delivery and low birth weight in term neonates were used as confirmatory outcome variables in the analysis. scriptive statistics were computed for all relevant data Association between Low maternal serum cholesterol and the two outcome variables were tested using chisquare. All significance are reported at $\mathrm{P}<0.05$.

Ethical approval for the study was obtained from the hospital's Health Research and Ethics committee prior to the commencement of the study and written consent obtained from each participant before involvement in the study.
The study was a prospective observational cohort study in which 320 pregnant women with singleton gestation between the gestational age of 14 and 20 weeks were enrolled at the point of sample collections. However on review of clinical data at delivery, $33(10.3 \%)$ of the ascertained cohort subjects were excluded. These included 16 women who were lost to follow-up while another 17 were excluded from the study based on the exclusion criteria ( 7 with medically indicated preterm delivery, 4 women who developed gestational hypertension, 2 women with gestational diabetes, 1 woman diagnosed with IUGR, 1 who had twin delivery, 1 whose neonate was diagnosed with structural cardiac defect delivery, and another 1 who had IUFD).

The final cohort available for analysis was therefore 28 representing $89.7 \%$ of the study patients) which included $26(9.1 \%)$ women with total cholesterol levels above the reference range $(200-239 \mathrm{mg} / \mathrm{dL}), 185(64.4 \%)$ with normal or mid-range levels and $76(26.5 \%)$ women with low total cholesterol levels.

When maternal characteristics were examined ac cording to the serum cholesterol levels (Table I \& II), there were no statistically significant differences found between the mothers with high total cholesterol and control subjects with normal total cholesterol with respect to the gestational age at enrolment for the study $(\mathrm{P}=0.935)$, gestation at delivery $(\mathrm{P}=1.001)$, parity $(\mathrm{P}=0.078)$, marital status $(\mathrm{P}=0.055)$, tribe $(\mathrm{P}=1.333)$, religion $(\mathrm{P}=0.097)$ and mode of delivery $(\mathrm{P}=0.788)$.

However, there were positive linear relationships between serum cholesterol levels with maternal age $(\mathrm{P}=0.014)$ and $\mathrm{BMI}(\mathrm{P}=0.039)$. A weak but statistically significant relationship was found between high total cholesterol and the upper socioeconomic class $(\mathrm{P}=0.045)$ when compared to women with normal total cholesterol.

TableI-Maternal serum cholesterol levels and Socio-demographic characteristics of study

patie
nts

\begin{tabular}{|c|c|c|c|c|}
\hline \multirow{4}{*}{ CHARACTERISTICS } & \multicolumn{3}{|c|}{ Study patients by cholesterol levels } & \multirow{5}{*}{ P-value } \\
\hline & High & Normal & Low & \\
\hline & & & & \\
\hline & $N=26$ & $\mathrm{~N}=\mathbf{1 8 5}$ & $N=76$ & \\
\hline $\begin{array}{l}\text { Cholesterol } \\
\text { Mean } \pm \text { SD (mg/dl) }\end{array}$ & $275.28 \pm 36.05$ & $227.59 \pm 11.34$ & $169.13 \pm 16.22$ & \\
\hline Maternal Age (years) & $33.73 \pm 5.14$ & $29.52 \pm 5.27$ & $24.75 \pm 5.24$ & 0.014 \\
\hline G.A at entry (weeks) & $19.72 \pm 1.48$ & $18.09 \pm 1.42$ & $19.27 \pm 1.37$ & 0.935 \\
\hline Maternal BMI (kg/m2) & $30.54 \pm 4.36$ & $29.05 \pm 4.54$ & $26.74 \pm 4.44$ & 0.039 \\
\hline G.A at delivery (weeks) & $37.17 \pm 2.41$ & $38.01 \pm 2.39$ & $37.99 \pm 2.43$ & 1.001 \\
\hline
\end{tabular}


TableII-Maternal serum cholesterol levels and Socio-demographic characteristics of study patients

\begin{tabular}{|c|c|c|c|c|}
\hline \multirow{3}{*}{ CHARACTERISTICS } & \multicolumn{3}{|c|}{ Study patients by cholesterol levels } & \multirow{3}{*}{ P-value } \\
\hline & High & Normal & Low & \\
\hline & $\mathrm{N}(\%)$ & $\mathrm{N}(\%)$ & $\mathrm{N}(\%)$ & \\
\hline \multicolumn{5}{|l|}{ PARITY } \\
\hline Primigravida & $7(26.9)$ & $34(18.4)$ & $8(10.5)$ & 0.078 \\
\hline Multigravida & $19(73.1)$ & $151(81.6)$ & $68(89.5)$ & \\
\hline \multicolumn{5}{|l|}{ MARITAL STATUS } \\
\hline Single & $10(38.5)$ & $25(13.5)$ & $6(7.9)$ & 0.055 \\
\hline Married & $16(61.5)$ & $160(86.5)$ & $70(92.1)$ & \\
\hline \multicolumn{5}{|l|}{ TRIBE } \\
\hline Hausa & $4(15.4)$ & $26(34.2)$ & $7(9.2)$ & 1.333 \\
\hline Ibo & $5(19.2)$ & $41(22.2)$ & $26(34.2)$ & \\
\hline Yoruba & 9 (34.6) & $91(49.1)$ & $35(46.1)$ & \\
\hline Others & $8(30.8)$ & $27(14.6)$ & $8(10.5)$ & \\
\hline \multicolumn{5}{|l|}{ RELIGION } \\
\hline Christianity & $12(46.2)$ & $120(64.9)$ & $48(63.2)$ & 0.097 \\
\hline Islam & $13(50.0)$ & $59(31.9)$ & $26(34.2)$ & \\
\hline Others & $1(3.8)$ & $6(3.2)$ & $2(2.6)$ & \\
\hline \multicolumn{5}{|l|}{ SOCIAL CLASS } \\
\hline Upper & $12(46.1)$ & $19(11.8)$ & $9(11.8)$ & 0.045 \\
\hline Middle & $8(38.8)$ & $147(79.5)$ & $37(48.7)$ & \\
\hline Lower & $6(23.1)$ & $19(10.2)$ & $30(39.5)$ & \\
\hline \multicolumn{5}{|l|}{ MODE OF DELIVERY } \\
\hline Vaginal delivery & $17(65.4)$ & $128(69.2)$ & $56(73.7)$ & 0.788 \\
\hline Caesarean section & $9(34.6)$ & $57(30.8)$ & $20(26.3)$ & \\
\hline
\end{tabular}

Table III showed that even among this low-risk cohort times more common with high total maternal choles of patients used in the study, the incidence of preterm terol than with normal maternal cholesterol $(38.5 \% \mathrm{vs}$. birth was found to be $8.0 \%$. Preterm birth was $6.89-5.4 \% ; \mathrm{P}=0.029$ ).
TableIII-Relationship between low maternal serum cholesterol and preterm delivery

\begin{tabular}{|c|c|c|c|}
\hline \multirow{3}{*}{ Serum cholesterol level } & \multicolumn{2}{|c|}{ Study patients } & \multirow[b]{2}{*}{ Total } \\
\hline & $\begin{array}{l}\text { Preterm delivery } \\
\quad(37 \text { wksG.A }) \\
\end{array}$ & $\begin{array}{l}\text { Term delivery } \\
(\geq 37 \mathrm{wksG} . \mathrm{A})\end{array}$ & \\
\hline & $N(\%)$ & $\mathrm{N}(\%)$ & \\
\hline High & $10(38.5)$ & $16(61.5)$ & $26(100.0)$ \\
\hline Normal & $10(5.4)$ & 175 (94.6) & $185(100.0)$ \\
\hline Low & $3(3.9)$ & $73(96.1)$ & $76(100.0)$ \\
\hline Total & $23(8.0)$ & $264(92.0)$ & $287(100.0)$ \\
\hline
\end{tabular}

P-value $=0.029 . \quad$ RR $=6.8917(95 \%$ CI-2.3897-11.3376)

In Table IV, the incidence of low birth weight (LBW) cholesterol $(87.5 \%$ vs. $10.5 \%, \mathrm{P}=0.019)$. Term infants in term babies was shown to be $14.4 \%$. LBW was 7.99 - born to mothers with high cholesterol had a much times more common in mothers with high total ma- lower average birth weight $(989.5-\mathrm{g})$ than those born to ternal cholesterol than in control mothers with normal control mothers with normal cholesterol levels (2460.5 vs. 3450.0-g).

Table IV-Relationship between serum cholesterol and LBW in term neonates

\begin{tabular}{|c|c|c|c|c|}
\hline \multirow[b]{3}{*}{ Serum cholesterol } & \multirow[b]{3}{*}{ Mean weight (g) } & \multicolumn{2}{|c|}{ Study patients } & \multirow{4}{*}{ Total } \\
\hline & & Low Weight & Normal Weight & \\
\hline & & (?2500g) & $(=2500 \mathrm{~g})$ & \\
\hline & & $\mathrm{N}(\%)$ & $\mathrm{N}(\%)$ & \\
\hline High & 2460.5 & $14(87.5)$ & $2(12.5)$ & $16(100.0)$ \\
\hline Normal & 3450.0 & $19(10.5)$ & $162(89.5)$ & $181(100.0)$ \\
\hline Low & 2350.0 & $5(7.5)$ & $62(92.5)$ & $67(100.0)$ \\
\hline Total & 2680.3 & 38 (14.4) & $226(85.6)$ & $264(100.0)$ \\
\hline
\end{tabular}

P-value=0.019. RR=7.9932 (95\% CI-5.8719-17.6011) 
This observational cohort study carried out among pregnant women at a tertiary hospital in South-west Nigeria examined how a substantially high value of maternal serum cholesterol levels in early pregnancy would affect and be used as predictor for later events, such as week of delivery and fetal growth.

Our study found an the incidence of $8.0 \%$ for preterm births in this highly selected study cohort which was only slightly higher than the figure reported by Edison et al $(6.6 \%)^{21}$, but it is still within the range quoted by Kierse at $5-10 \%{ }^{22}$ and from a study done in Nigeria by Ezechukwu et al $(5-25 \%)^{23}$. This was probably due to the similarities in the study groups used in all these studies especially with regard to the patients' age range. Preterm birth is known to be initiated by multiple mechanisms and various reports have suggested a possibly increased risk for prematurity with very high maternal cholestero ${ }^{12,24,25}$. Finding by Catov and coworkers ${ }^{26}$ showed that an elevation in maternal cholesterol level early in gestation was associated with an increased risk of preterm delivery. This was corroborated by the finding from this present cohort study where we reported an elevated risk for preterm birth among mothers with high maternal cholesterol.

LBW was reported to occur in $14.4 \%$ of the term born infants in our study. This prevalence is slightly higher than the estimate of $10.0 \%$ reported by UNICEF among full term new born infants in developing countries $^{27}$ but it's within the incidence of $6-21 \%$ reported by Lawoyin et $\mathrm{al}^{28}$.

The working hypothesis for this study that the risk for low birth weights would be increased among infants who are born to mothers with high maternal serum cholesterol was also confirmed statistically; the statistical trend estimated a seven-fold increase in risk in mothers with high total maternal cholesterol compared to control mothers with normal cholesterol. This positive correlation was consistent with the finding by Fakhar-un-Nisa et a ${ }^{25}$.

\section{Limitations to the study}

Since the study is hospital based, there was selectionbias in the enrolment of participants thus limiting the generalizability of the study to the whole population. The incessant strike action by the hospital staff also resulted in a higher than expected fall-out rate of the extripants in the study.

\section{Conclusion}

We can infer from this study that increase maternal age and high maternal BMI are associated with high maternal serum cholesterol (hypercholesterolaemia) which in turn is associated with preterm birth and low birth weight in term neonates. We therefore recommend that further validation of these findings with more robust prospective and longitudinal characterization of maternal serum cholesterol profiles in pregnancy, with elimination of major confounding variables such as maternal age and BMI, be carried out in subsequent investigations to determine the optimal cholesterol range in pregnancy, and until such more studies are performed, pregnant women should be encouraged to

fow a healthy, balanced diet and regular antenatal visit to their healthcare provider.

\section{Source(s) of support:}

None

Conflicting Interest:

None declared

\section{References}

1. Meis PJ, Klebanoff M, Thom E, Dombrowski MP, Sibai B, Moawad AH, Spong CY, Hauth JC et al. Prevention of recurrent preterm delivery by 17 alpha-hydroxyprogesterone caproate. NEJM 2003; 348(24):2379-85. 2. Woollett LA. The origins and roles of cholesterol and fatty acids in the fetus. Curr Opin Lipidol.2001;12 :305-312.

3. Tuckey RC. Progesterone synthesis by the human placenta. Placenta.2005;26:273-281

4. Henson MC, Shi W, Greene SJ, Reggio BC. Effects of pregnant human, non-pregnant human and fetal bovine sera on human chorionic gonadotropin, estradiol, and progesterone release by cultured human trophoblast cells. Endocrinology.1996;137:20672074.

5. Winkler K, Wetzka B, Hoffmann MM, et al. Low density lipoprotein (LDL) subfractions during pregnancy: accumulation of buoyant LDL with advancing gesClin Endocrinol Metab.2000;85:4543- 4550.

6. Alvarez JJ, Montelongo A, Iglesias A, Lasuncion MA, Herrera E. Longitudinal study on lipoprotein profile, high density lipoprotein subclass, and postheparin lipases during gestation in women. J Lipid Res.1996;37 :299- 308.
7. Brizzi P, Tonolo G, Esposito F, et al. Lipoprotein metabolism during normal pregnancy. Am J Obstet Gy necol.1999;181:430- 434

8. Tranquilli AL, Cester N, Giannubilo SR, Corradetri A, Nanetti L, Mazzanti L. Plasma lipids and physicochemical properties of the erythrocyte plasma membrane throughout pregnancy. Acta Obstet Gynecol Scand. 2004:83:443- 448

9. Napoli C, D'Armiento FP, Mancini FP, et al. Fatty streak formation occurs in human fetal aortas and is greatly enhanced by maternal hypercholesterolemia. In timal accumulation of low density lipoprotein and its oxidation precede monocyte recruitment into early atherosclerotic lesions. I Clin Invest.1997;100:26802690. 10. Napoli C, Glass CK, Witztum JL, Deutsch R, Outcome among Mothers With Low Serum CholesterD'Armiento FP, Palinski W. Influence of maternal hy- ol. Pediatrics. 2007; 120; 723-733.

percholesterolaemia during pregnancy on progression 22. Kierse MJNC:New perspectives for the effective of early atherosclerotic lesions in childhood. Fate of treatment of preterm labour. American Journal of Obstet 354: 1234-1241

2. Skilton MR, Evans N, Griffiths KA, Harmer JA, Celermajer DS. Aortic wall thickness in newborns with intrauterine growth restriction. Lancet. 2005;365:1484 1486.

3. Coukos G, Gafvels ME, Wittmaack F, et al. Potential roles for the low density lipoprotein receptor family of proteins in implantation and placentation. Ann N Y Acad Sci.1994;734:91-102

14. Misra VK, Trudeau S, Perni U. Maternal serum lipids during pregnancy and infant birth weight: the influence of prepregnancy BMI. Obesity (silver Spring). PubMed NCBI.2011;19(7):1476-81.

15. Khoury J, Henriksen T, Christophersen B, Tonstad S. Effect of a cholesterol-lowering diet on maternal, cord, and neonatal lipids, and pregnancy outcome: a randomized clinical trial. Am J Obstet Gynecol.2005; 193 :1292-1301. et al. Preterm delivery and later maternal carstudies of disease. Am J. Epid. ; vol 99 No.6: 381-384. diatr 1985; 12(4): 111-117.

SPS System for Windows computer proram]. Version 17. Cary, NC: SPSS Institute Inc; 2008 rics and Gynaecology 1995; 173: 618-28.
23. Ezechukwu CC, Ugochukwu EF, Egbuonu I 23. Ezechukwu CC, Ugochukwu EF, Egbuonu
Chukwuka JO. Risk factors for neonatal mortality in a regional tertiary hospital in Nigeria. Nig J Clin Pract 2004; 7: 50-2.

24. Vanderjagt DJ, Patel RJ, El Nafaty AU, Melah GS, Crossey MJ, Glew RH. High-density lipoprotein and homocysteine levels correlate inversely in preeclamptic women in northern Nigeria. Acta Obstet Gynecol Scand.2004; 83: 536- 542

25. Fakhar-un-Nisa, Jafri SA, Kousar S, Rakhashand J. Correlation of gestatiponal lipid profile with neonatal birth weight. Biomedical; 2011: vol 27. Pg 68-71. 26. Catov JM, Newman AB, Kelsey SF, Suton-Tyrell K, Harris TB, et al Preterm delivery and later maternal cardiovascular disease risk. Epidemiol, 2007; 18: 733-739 27. UNICEF. The State of the World's Children. United Nations Children's Fund 2000.

28. Lawoyin TO, Oyediran ABO. A Prospective Study on some Factors which Influence the Delivery of Low Birth Weight Babies in a Developing Country. Afr. J. Med. Sci., 1992; 21(1): 33-39. 